\title{
Cardiovascular events in chronic kidney disease (CKD) - an importance of vascular calcification and microcirculatory impairment
}

\author{
Shuzo Kobayashi
}

\begin{abstract}
In patients with chronic kidney disease (CKD), particularly in patients with hemodialysis, cardiovascular mortality rate is extremely high. Polyvascular diseases develop at an early stage of CKD. Pathophysiology includes insulin resistance and/or imbalance between nitric oxide (NO) and endothelin bioavailability as well as oxidative stress. Overlooked pathophysiology may be hemorheological disarrangement because of hyperfibrinogenemia, and higher rate of production for monocyte-platelet complexes in circulation, which plays an important role for atherosclerosis. In terms of clinical findings, most of nephrologists have already known about the importance of coronary artery disease, while few of nephrologists are aware of devastating influence of peripheral arterial disease (PAD) on prognosis for the patients with CKD which is known to be one of the independent risk factors for PAD. The understanding in pathophysiology of vascular calcification and strategic treatment is a critical issue to achieve favorable outcome for the patients with CKD. In this regard, FGF-23 and associated factors together with Klotho molecules play an important role.

In this article, we aim to review the cardiovascular disease for the patients with CKD with a particular emphasis on the clinical aspects of polyvascular disease. Finally, we address to detect microcirculatory impairment and eradicate vascular calcification as early as possible prior to renal replacement therapy. Apparently, FGF-23-Klotho gene axis as well as vitamin $\mathrm{D}$ and phosphate control should be investigated vigorously.
\end{abstract}

\section{Background}

It is well known that cardiovascular events (CVE) increase as renal function declines [1]. Ohtake et al. have reported that when renal replacement therapy (RRT) begins, approximately $50 \%$ of the patients with chronic kidney disease (CKD) have significant coronary artery stenosis regardless of the presence or absence of symptoms and/or signs. If the patients have diabetes, the prevalence is reported to reach $89.9 \%$ [2]. In this report, all patients have no cardiac-related symptoms or signs nor any treatment including percutaneous coronary intervention (PCI), except hypertension. Although we had reported that hypertension was an important risk factor of lacunar infarction [3], we also revealed that

Correspondence: shuzo@shonankamakura.or.jp

Department of Kidney Disease and Transplant Center, Shonan Kamakura General Hospital, 1370-1 Okamoto, Kamakura 247-8533, Japan decreased GFR is an independent risk factor for lacunar infarction irrespective of the presence or absence of symptoms [4]. These surprising results let us investigate when and how cardiovascular complications develop during a decrease in GFR. At the same time, it was reported that CKD per se was an independent risk factor for cardiovascular disorders (CVD) as an important statement of AHA [5].

In this regard, the term, "polyvascular disease" has been proposed [6, 7]. Polyvascular disease is defined as coexistent symptomatic (clinically recognized) arterial disease in two or three territories (coronary, cerebral, and/or peripheral) with each patient $[6,7]$. Moreover, with regard to the pathophysiology of atherosclerosis based on uremia, it has been demonstrated that oxidative stress, thus leading to endothelial dysfunction, plays an important role $[8,9]$. We have focused on insulin resistance because insulin 
resistance is well known to be involved in endothelial dysfunction [10]. Given that mineral and bone disorder plays an important role in the patients with CKD, we need to understand an impact of vascular calcifications on outcome of CVD, because it makes an intervention difficult. In particular, the evidence that coronary calcification develops at an early stage of CKD has been found with important findings showing the roles of insulin resistance and asymmetric dimethylarginine (ADMA) [11]. Moreover, because overlooked findings are the issue concerning hemorheology [12], we investigate a role of rheology $[13,14]$.

Of CVE, peripheral arterial disease (PAD), which means in this context chronic atherosclerosis obliterans (ASO) in the lower limbs, should be investigated more sufficiently, given extremely poor prognosis after amputation in hemodialysis patients [15].

\section{Insulin resistance and CKD}

It has been shown that insulin resistance may contribute to the pathogenesis of atherosclerotic cardiovascular disease [16]. It is widely known that hypertension and hyperlipidemia play important roles in the progression of renal disease [17] and that insulin resistance may be involved in the pathogenesis of hypertension [18]. Moreover, nutritional, metabolic, and cardiovascular complications of renal disease may be consequences of abnormal insulin action [19]. Therefore, long-standing renal dysfunction may cause atherosclerosis prior to the initiation of dialysis therapy. We have already reported that both modalities of RRT, hemodialysis (HD), and continuous ambulatory peritoneal dialysis (CAPD) improve insulin resistance in patients with ESRD [20]. It goes without saying that insulin resistance remains among some patients after initiation of renal replacement. It is reported that even in hemodialysis patients, insulin resistance is an independent predictor of cardiovascular mortality in ESRD [21]. In CAPD patients, glucose load during treatment affects insulin resistance, which is associated with obesity [22].

All reports published recently show that insulin resistance is present early in the course of renal disease [23-26]. However, a more precise method, hyperinsulinemic euglycemic glucose clamp, to evaluate insulin sensitivity developed by DeFronzo et al. [27-29] has not been applied to these studies. In addition, except classical risk factors such as dyslipidemia or diabetes mellitus, affecting renal-related factors associated with insulin resistance or apolipoprotrein profiles have not yet been shown.

To address this issue in Japanese nondiabetic patients, we carried out the hyperinsulinemic euglycemic glucose clamp technique [30] to examine insulin sensitivity in patients with different stages of renal function including the stage just prior to the initiation of RRT and related this with various affecting variables found in CKD. In healthy subjects, the glucose disposal rate (GDR) was $9.93 \pm 1.33 \mathrm{mg} / \mathrm{kg} / \mathrm{min}$. In contrast, the GDR of patients with CKD was $6.91 \pm 2.46 \mathrm{mg} / \mathrm{kg} / \mathrm{min}$ significantly lower than that of healthy subjects $(P<0.01)$, which means diminished insulin sensitivity in patients with CKD. There was a negative correlation between the GDR and serum creatinine levels $(r=0.457, P<0.05)$ (Fig. 1$)$ and positive correlations between the GDR and Ccr $(r=0.549, P<$ $0.01)$ or ApoA1/B $(r=0.396, P<0.05)$. Of particular relevance is the observed close correlation between the GDR and $\mathrm{HCO}_{3}$ with extremely high predictive value for the degree of acidosis $(r=0.611, P<0.0005)$. Stepwise multivariate regression analysis selected $\mathrm{HCO}_{3}(F$ value $13.28)$ and Apo A1/B (F 6.58) as independent contributing variables. The present study has many implications for the management of renal patients before the initiation of RRT because the discovered link between insulin resistance and cardiovascular mortality in patients with the metabolic syndrome. Every possible therapeutic approach needs to be initiated very early to correct the atherogenic metabolic profile. Particularly, the data suggested that acidemia should be corrected as early as possible. Likewise, statin treatment may be used for the correction of apolipoprotein profiles [31]. With regard to the correction of acidemia, it has been reported that the correction retards the progression of CKD [32]. It became more evident that nontraditional risk factors including insulin resistance, acidemia, and apolipoprotein would be involved in CVD found in CKD.

In addition to the factors described above, chronic inflammation, oxidative stress, angiotensin II, and aldosterone also are known to be involved in insulin resistance. With regard to mineral corticoid, it has been reported that in a patient cohort with nondiabetic stage 2-5 CKD, estimated glomerular filtration rate (eGFR) was negatively correlated and the plasma aldosterone concentration was independently associated with the homeostasis model assessment of insulin resistance. In this report, spironolactone ameliorated insulin resistance in these patients [33]. So far, there have been known many factors that affect insulin resistance in CKD as shown in Table 1.

\section{Vascular calcification and insulin resistance in CKD}

Coronary artery calcification $(\mathrm{CAC})$ is regarded as an index of the severity of atherosclerotic vascular disease and may predict future adverse cardiovascular events in patients on dialysis [34-36]. In patients with CKD prior to initiation of RRT, CAC is already present in the early phase of CKD [37-39] and among diabetic nephropathy [40]. Associated factors with CAC besides age, calcium, phosphorus, $\mathrm{PTTH}$, and inflammation have not been fully elucidated. Arad et al. have reported that asymptomatic 


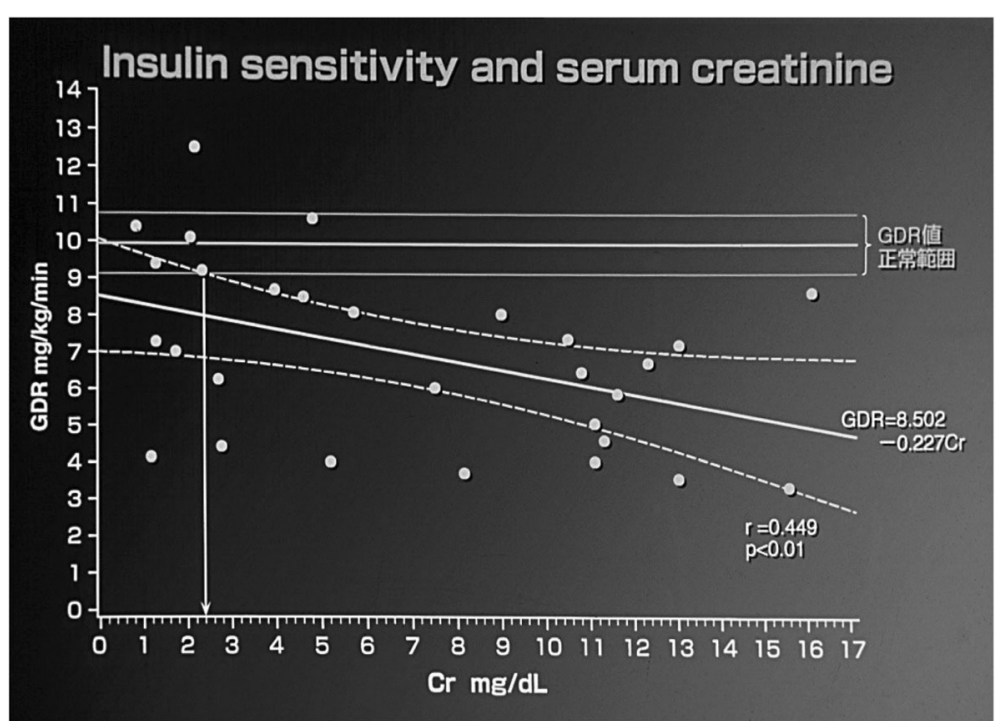

Fig. 1 Insulin resistance develops at an early stage in CKD. The patients with at least serum creatinine more than $2 \mathrm{mg} / \mathrm{dl}$ clearly have insulin resistance with hyperinsulinemic euglycemic glucose clamp method. GDR stands for glucose disposal rate, which is equivalent to glucose infusion rate in order to set $100 \mathrm{mg} / \mathrm{dl}$ of serum glucose levels under insulin infusion

individuals with insulin resistance have elevated coronary calcification in general populations [41]. However, it remains unknown whether insulin resistance is also correlated with $\mathrm{CAC}$ in $\mathrm{CKD}$ patients. Insulin resistance leading to atherosclerosis may be explained by increased plasma levels of ADMA, which is an endogenous nitric oxide synthase inhibitor [42]. Concentrations of ADMA are related to endothelial dysfunction [43, 44] because increased ADMA may impair blood flow, accelerate atherogenesis, and interfere with angiogenesis by inhibiting the production of nitric oxide [45]. Of note, ADMA concentrations are higher in dialysis patients with

Table 1 Factors affecting insulin resistance

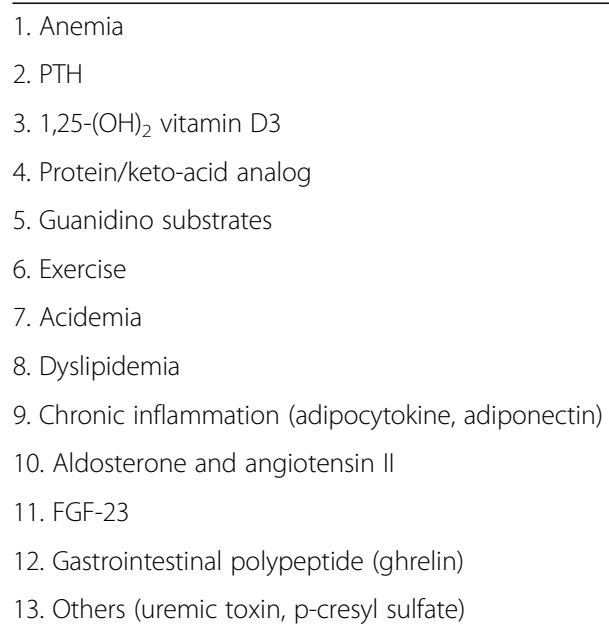

clinically manifest atherosclerosis than in those without atherosclerotic disease [46], which suggests that accumulation of ADMA might be an important cardiovascular risk factor in end-stage renal disease. Moreover, the clinical importance of ADMA in coronary artery disease is highlighted in a trial by Meinitzer et al. [47], in which ADMA predicted cardiovascular events in 3200 patients. In addition, ADMA predicts coronary events in middleaged Caucasian men [48].

With this background in mind, we aimed to study the prevalence and associated factors of CAC in CKD patients prior to initiation of RRT [11]. Particularly, we wanted to know whether insulin resistance and/or plasma levels of ADMA would be correlated with CAC. One hundred and eleven CKD patients (79 men, 32 women, GFR median $33.7 \mathrm{ml} / \mathrm{min} / 1.73 \mathrm{~m}^{2}$ ), free of cardiovascular disease, were consecutively recruited along with 30 age-matched healthy subjects. Coronary artery calcification scores (CACS) were measured by multidetector-row CT (MDCT) according to Agatston score, and insulin resistance was estimated by HOMAIR. In CKD patients, CACS was distributed widely from 0 to 2901(median 45), while in age-matched, healthy control subjects $(n=30)$, CACS showed a range from 0 to 307 (median 2.8). GFR had a significant negative correlation with CACS $(r=0.218, P<0.05)$ (Fig. 2). Plasma ADMA levels were negatively correlated with GFR ( $r=$ $-0.551, P<0.001)$ and positively correlated with CACS $(r=0.259, P<0.05)$. When CACS was divided into quartiles $(<50, n=56 ; 50 \sim 300, n=24 ; 300 \sim 600, n=14 ;>600$, 


\section{GFR and Coronary artery calcification (CACS)}

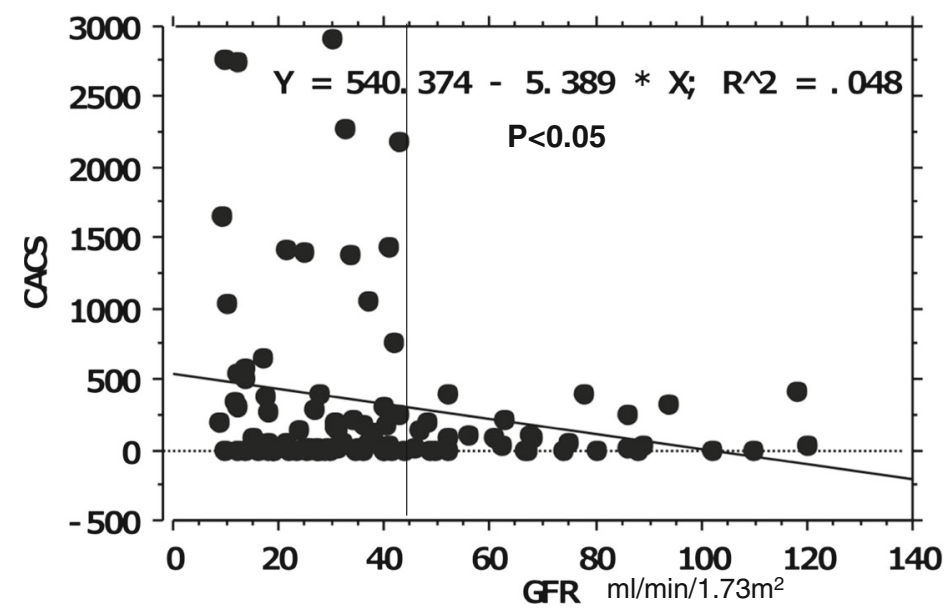

Fig. 2 Coronary artery calcification assessed by Agatston calcium score (CACS) increases with a decline of GFR, when particularly in patients with less than $45 \mathrm{ml} / \mathrm{min} / 1.73 \mathrm{~m}^{2}$ of GFR, CACS is found to be abruptly increased

$n=17)$, the patients with CACS above 600 had significantly higher values of HOMA-IR, plasma ADMA levels, and fibrinogen along with serum levels of phosphorus, compared with those in patients having CACS below 50. Multivariate regression analysis determined HOMA-IR (95 \% CI 4.15-32.3, $\beta$ value $0.257, P=0.011$ ) as an independent contributing factor to CACS. We demonstrated that $\mathrm{CAC}$ becomes more prevalent and severe with a decline in GFR, and plasma ADMA levels and insulin resistance, independent of factors associated with CKD-MBD, are correlated with CAC [11]. Despite the abovementioned findings, we should also know the evidence that HOMA-IR was not predictive after adjustment for metabolic syndrome components [49].

\section{Hemorheological properties in CKD}

Atherosclerosis is not a single disease entity, but a process consisting of responses to numerous insults to the endothelium, which plays an important role for atherosclerosis. These cells function as a protective biocompatible barrier between all tissues and the circulating blood [50]. Therefore, endothelial cells are likely to sense the changes in hemodynamic forces and blood-borne signals. Injured endothelial cells are predisposed to vasoconstriction, leukocytes adherence, platelet activation, mitogenesis, and oxidation, all of which lead to atherosclerosis. Particularly, evidence suggests that leukocytes may play an active role in the modulation of platelet function and vice versa [50]. The formation of leukocyte aggregates (LA), particularly platelet-leukocyte aggregates, during HD may play an important pathophysiological role by facilitating platelet-endothelial interaction [51]. Indeed, in myocardial infarction, and angina pectoris, it has been reported that total binding of platelets to monocytes increases, and there is an evidence showing that $P$ selectin-independent molecular component plays an important role [52].

We report [13, 14] that blood rheology could be successfully evaluated using a micro-channel array flow analyzer (MC-FAN) that makes it possible to directly observe the flow of blood cell elements through the micro-channel. Originally, in order to assess hemorheological characteristics, MC-FAN was developed to measure the transit time of $50 \mu \mathrm{l}$ of whole blood through micro-channels. During our measurement of the transit time, we noticed many aggregates of blood cell elements in micro-channels in patients with HD. Using this method, we wanted to show a significance of aggregates of blood cell elements found during blood flow through the microchannel array. This study sought to assess the relationship between leukocytes conjugated with platelets (LA) and atherosclerosis in patients with HD. The study included 118 patients on dialysis. As surrogate markers of atherosclerosis, aortic stiffness measured by brachial-ankle pulse wave velocity (baPWV) and carotid intima-media thickness (IMT) were measured. We measured a number of LA during $50-\mu$ l flow of whole blood through micro-channels. In 12 age-matched healthy individuals, a number of LA during $50-\mu$ l flow of whole blood were $25.7 \pm 5.4$, whereas in dialysis patients, it was significantly increased up to $48.2 \pm 16.4(P<0.001)$. Flow 
cytometry demonstrated that LA were predominantly monocyte-platelet complex. LA were positively associated with plasma levels of fibrinogen $(P<0.01)$ or serum hsCRP $(P<0.01)$. Moreover, LA had highly significant associations with baPWV $(P<0.001)$ and IMT $(P<0.001)$.

As conclusions, we demonstrated hemorheologically that monocyte-platelet conjugates play an important role in aortic stiffness and IMT in CKD patients.

\section{Peripheral arterial disease in CKD—an importance of an early detection of microcirculatory impairment prior to dialysis}

Peripheral arterial occlusive disease (PAD) influences the mortality of patients on HD [53]. The early detection of PAD is extremely important to improve the prognosis of these patients. In this regard, various noninvasive methods have been applied to the diagnosis of patients with PAD [54-56]. The ankle-brachial blood pressure index (ABI) is correlated well with the severity of PAD symptoms and with the angiographic findings [56-59]. Therefore, the ABI is used as a standard tool for classifying the severity of PAD or for assessment of the presence of critical limb ischemia [60,61].

However, arterial rigidity associated with medial calcification may interfere with the measurement of ABI. Indeed, there are some cases in which it may be difficult to detect isolated obstruction in one or even two of the three branches of the popliteal artery between the knee and ankle or obstruction in more distal vessels $[56,59]$. These false-negative results occur in 17 to $24 \%$ of diabetic limbs and have also been reported in patients undergoing HD or in other elderly patients [56, 62, 63]. Although usefulness of the toe-brachial pressure index (TBI) or transcutaneous oxygen tension $\left(\mathrm{tcPO}_{2}\right)$ has been reported [64], Castronuovo et al. found that the skin perfusion pressure (SPP) is an objective and noninvasive method that can be used to diagnose critical limb ischemia with an accuracy of approximately $80 \%$ in non-hemodialysis patients [65]. In the diabetic foot, SPP is known to be correlated well with TBI [66]. Regarding which of the noninvasive methods among ABI, TBI, $\mathrm{tcPO}_{2}$, and SPP is superior to the others, we showed that SPP is superior to others in terms of sensitivity and specificity [67]. The reason why ABI yields false-negative results in HD patients may be greatly due to the fact that the lesions in these patients often have arterial calcification in addition to their location being in the more distal parts of the lower limb arteries. We need to be aware that microcirculatory impairment should be detected as early as possible and take an action for the treatment of vascular calcification.

In order to improve the outcome of PAD, it is extremely important to make intervention strategies for
PAD [68]. Because the outcome for patients with foot gangrene is poor, it is important to detect PAD as early as possible prior to the initiation of dialysis. Leskinen et al. [69] demonstrated that the patients with CKD (mean creatinine levels $3.64 \pm 1.53 \mathrm{mg} / \mathrm{dl}$ ) prior to the initiation of dialysis had PAD in $22 \%$ and medial arterial calcification in $23.7 \%$. It has been also reported [70] that $32 \%$ of patients had an ABI $<0.9$ in the patients with CKD $3 \sim 5$ of K/DOQI (mean eGFR $35 \pm 12 \mathrm{ml} / \mathrm{min} / 1.73 \mathrm{~m}^{2}$ ), and by the logistic regression analysis, independent indicators of PAD risk were male sex, age, and lower Ccr. Twelve percent of patients had an $A B I \geq 1.3$, suggestive of parietal arterial calcifications. In these patients, systolic blood pressure and pulse pressure were lower, iPTH levels were higher, and a larger proportion of this group was treated with calcitriol (34 vs. $13 \%$ ) compared to patients with a normal ABI. It is concluded that a high prevalence of PAD, considered as an $\mathrm{ABI}<0.9$, was demonstrated in nondialyzed patients with CKD. This was related with age, male sex, and higher degree of renal insufficiency, while the presence of $\mathrm{ABI} \geq 1.3$ was associated with a greater degree of hyperparathyroidism. These data show the need to carry out at least routine ABI determinations including TBI in patients with CKD for early detection of peripheral arterial disease, and further SPP would be more useful to detect microcirculatory impairment. Regarding the treatment for the patients with an ABI of 1.3 or higher, it is extremely an important issue in terms of a prevention of vascular calcification. Thus, strict control of phosphorus as well as avoiding drugs such as calcium-containing phosphate binders or warfarin which is known to decrease matrix-gla protein working as a local inhibitor of calcification [71].

\section{CKD-MBD and vascular calcification-a role of FGF-23 and phosphate control}

It has been well known [72] that serum phosphate levels are associated with mortality. Kestenbaum et al. reported that after adjustment for confounding factors, serum phosphate levels $>3.5 \mathrm{mg} / \mathrm{dl}$ were associated with a significantly increased risk for death. Mortality risk increased linearly with each subsequent $0.5-\mathrm{mg} / \mathrm{dl}$ increase in serum phosphate levels. Elevated serum phosphate levels were independently associated with increased mortality risk among this population of patients with CKD. There are several factors that affect vascular calcification (Fig. 3). Pathogenesis of vascular calcification is not merely the passive precipitation of calcium and phosphate crystals but more active process of trans-differentiation of vascular smooth muscle cells into osteoblast-like cell. The 


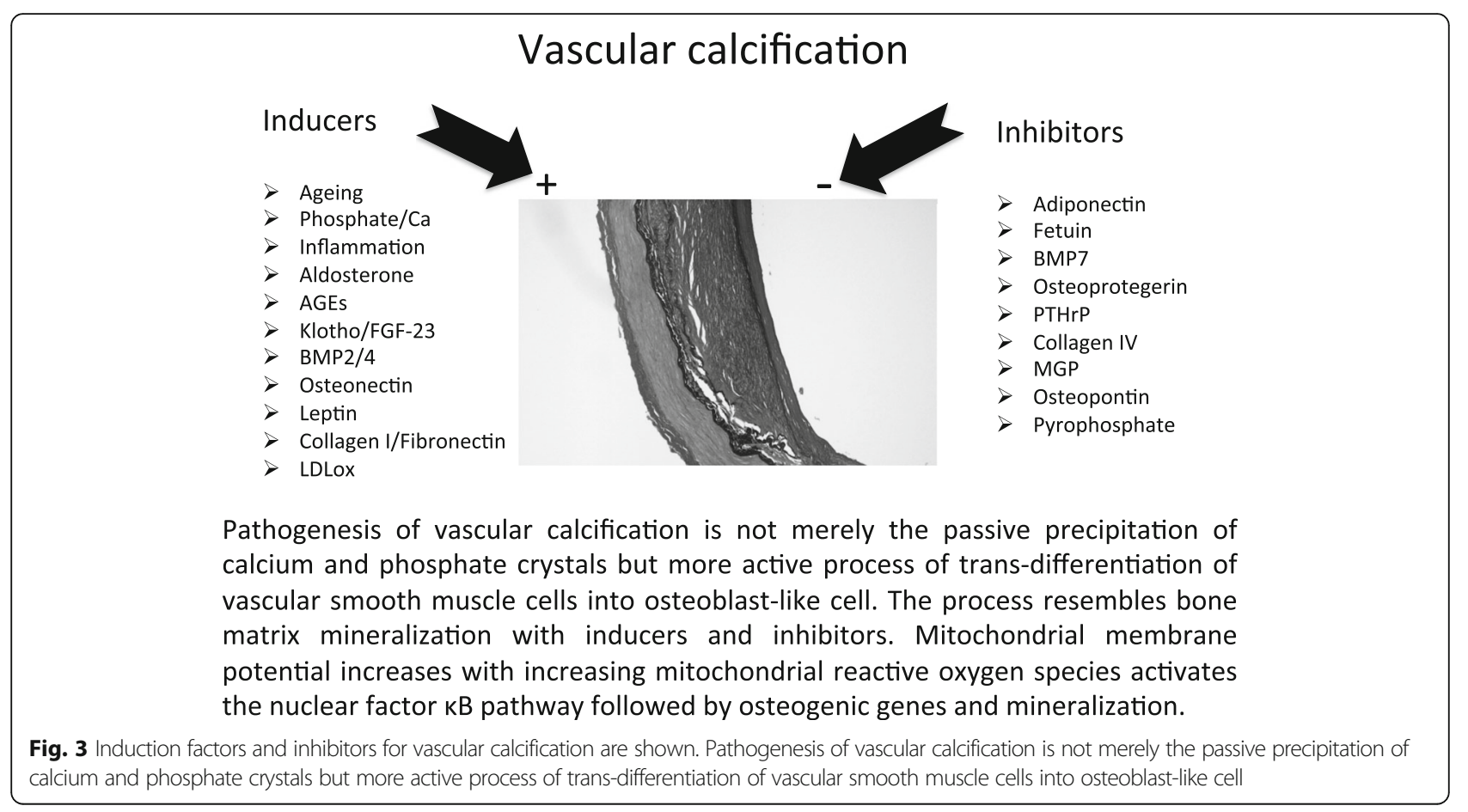

process resembles bone matrix mineralization with inducers and inhibitors. Mitochondrial membrane potential increases with increasing mitochondrial reactive oxygen species, which activates the nuclear factor $\mathrm{kB}$ pathway followed by osteogenic genes and mineralization. Of them, serum phosphate control and discontinuation of drugs, which worsen vascular calcification, can be achieved practically. Warfarin is known to decrease active MGP (matrix-gla protein), which is working as local inhibitor for calcification, thus leading to calcification. The pathophysiology of vascular calcification is beyond the scope of this review. However, it is very important to understand the rationale and approaches to phosphate and FGF-23 reduction in CKD [73]. Isakova et al. noted that observational studies report independent associations between elevated serum phosphate and fibroblast growth factor 23 (FGF-23) levels and risks of ESRD, CVD, and death. Phosphate excess induces arterial calcification, and although elevated FGF-23 helps maintain serum phosphate levels in the normal range in CKD, it may contribute mechanistically to left ventricular hypertrophy (LVH). Consistent epidemiologic and experimental findings suggest the need to test therapeutic approaches that lower phosphate and FGF-23 in CKD.

Recently, Klotho gene was identified as a gene mutated in a mouse strain that developed a premature aging syndrome. A defect in Klotho gene expression in mice results in shortened life span, muscle atrophy, vascular calcification, osteopenia, cognitive impairment, all of which are found in CKD patients [74]. Moreover, the fact that FGF23 requires Klotho as a co-receptor explains why Klotho-deficient mice develop phenotypes identical with those observed in FGF23-deficient mice and why Klotho-deficient mice had extremely high serum FGF23 levels. Taken together, we need to vigorously investigate FGF-23Klotho gene axis, in other words, kidney-bone axis as well as vitamin D deficiency when we discuss about cardiovascular complications. Indeed, it is reported that lower 25-hydroxyvitamin D concentrations associate with increased risk for incident $\mathrm{CAC}$, and accelerated development of atherosclerosis may underlie, in part, the increased cardiovascular risk associated with vitamin D deficiency [75].

Apparently, we need to continue researching a role of FGF-23 regarding cardiovascular events in progressive stage in CKD prior to renal replacement therapy. Recently, it has been reported that in the prospective observational study of limited sample size, soluble Klotho was not significantly related to cardiovascular outcomes. FGF-23 was significantly associated with future decompensated heart failure (CHF) but not incident atherosclerotic events [76]. An elevated level of fibroblast growth factor-23 (FGF23) is the earliest abnormality of mineral metabolism in CKD. High FGF-23 levels promote left ventricular hypertrophy but not coronary artery calcification. Higher FGF-23 is independently associated with greater 
risk of cardiovascular events, particularly CHF, in patients with CKD stages 2-4 [77].

\section{Uric acid and cardiovascular events in CKD}

Recent epidemiologic and experimental evidence suggest that serum uric acid (UA) is an independent risk factor for cardiovascular and renal diseases. The data show an independent link between UA and endothelial function, also in a statistical model that included CRP [78].

UA may mediate aspects of the relationship between hypertension and kidney disease via renal vasoconstriction and systemic hypertension. An elevated serum UA level is an independent risk factor for incident kidney disease in the general population [79]. Recently, it has been reported that febuxostat slowed the decline in eGFR in CKD stages 3 and 4 compared to placebo [80]. Asymptomatic hyperuricemia could be an important target to slow the progression of CKD as well as a prevention of cardiovascular disorders. Regarding uric acid levels and mortality, it is reported that in multivariable models, a J- or U-shaped relationship between serum uric acid level and total or cause-specific cardiovascular mortality is observed. There was not a linear increase in mortality from almost all causes of death associated with the increase in serum uric acid levels [81].

\section{Conclusions}

Although an important role of dyslipidemia and hypertension was not described in this review, needless to say, both has been long investigated regarding cardiovascular complications in CKD.

Since Russell Ross reported the response-to-injury hypothesis of atherosclerosis in 1976 followed by its update in 1986, endothelial dysfunction with an important role of monocytes-platelets has been investigated [82, 83]. Moreover, arterial intima and media calcification both affect vascular calcification, which make the diagnosis and treatment extremely difficult. The media calcification was described in 1903 Mönckeberk's mediasclerosis after Professor Mönckeberg, pathologist, at University Strasbourg [84]. Based upon these reasons, cardiovascular events in CKD occur under the pathophysiology of "vascular failure," which mean that intima and media both in vessels are injured (Fig. 4). Increase pulse pressure due to vascular calcification plays an important role of cardiac afterload and endothelial dysfunction, which leads to vicious cycle for the progressive stage of vascular injury leading to inflammation (Fig. 5).

Microcirculatory impairment and vascular calcification through endothelial dysfunction based on insulin resistance should be detected as an early stage as

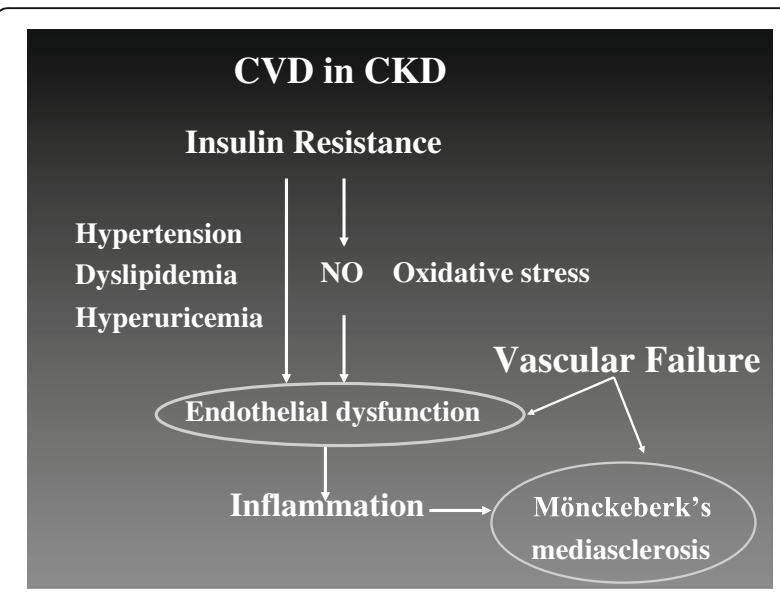

Fig. 4 Basic characteristics in pathophysiology of cardiovascular disease in patients with CKD are shown. Cardiovascular complications in CKD occur under the pathophysiology of "vascular failure," which means that intima and media both in vessels are injured through nitric oxide and/or oxidative stress as well as hypertension, dyslipidemia, and hyperuricemia

possible in CKD. Treatment strategies including phosphate, which indeed impairs endothelial function through a reduction of nitric oxide production [85], and correction of insulin resistance as well as traditional treatment modalities are fundamental to improve cardiovascular complications in CKD. Nephrologists should be aware to treat the patients with CKD in terms of polyvascular disease.

Apparently, FGF-23-Klotho gene axis as well as vitamin D and phosphate control should be investigated vigorously although precise roles of FGF-23 still remain controversial [86].

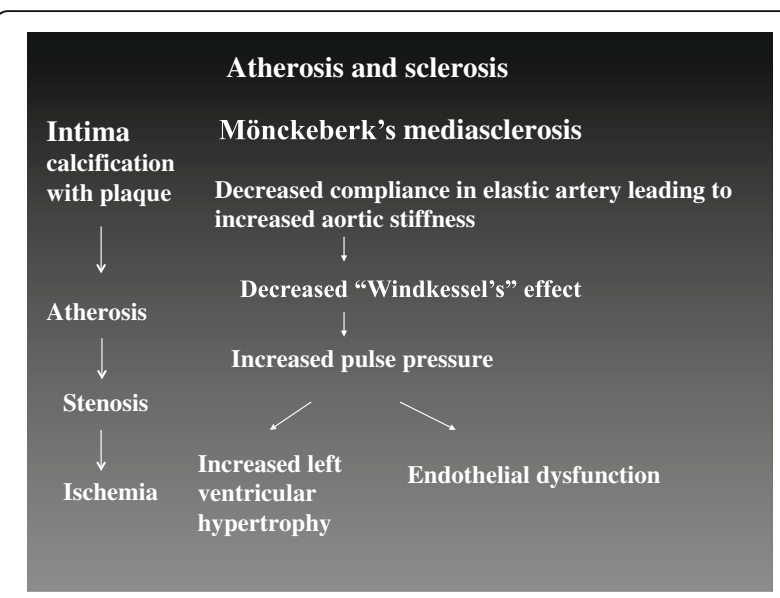

Fig. 5 Increase pulse pressure due to vascular calcification plays an important role of cardiac afterload and endothelial dysfunction, which leads to vicious cycle for the progressive stage of vascular injury leading to inflammation 


\section{Competing interests}

The author declares that he has no competing interests.

Received: 28 June 2016 Accepted: 20 August 2016 Published online: 18 October 2016

\section{References}

1. Go AS, Chertow GM, Fan D, McCulloch CE, Hsu CY. Chronic kidney disease and the risks of death, cardiovascular events, and hospitalization. N Engl J Med. 2004;351:1296-305.

2. Ohtake T, Kobayashi S, Moriya H, Negishi K, Okamoto K, Maesato K, Saito S High prevalence of occult coronary artery stenosis in patients with chronic kidney disease at the initiation of renal replacement therapy. Anangiographic examination. J Am Soc Nephrol. 2005;16:1141-8.

3. Ikeda T, Gomi T, Kobayashi S, Tsuchiya H. Role of hypertension in asymptomatic cerebral lacunae in the elderly. Hypertension. 1994;23 Suppl 1:1259-62.

4. Kobayashi S, Ikeda T, Moriya H, Ohtake T, Kumagai H. Asymptomatic cerebral lacunae in patients with chronic kidney disease. Am J Kidney Dis. 2004:44:35-41.

5. Sarnak MJ, Levy AS, Schoolwerth AC, Coressh J, Culleton B, Hamm LL, MaCullough PA, Kasiske BL, Kelepouris E, Klag MJ, Parfey M, Raij L, Spinosa DJ, Wilson PW. Kidney disease as a risk factor for development of cardiovascular disease: a statement from the AHA councils on kidney in cardiovascular disease, high blood pressure research, clinical cardiology, and epidemiology, and prevention. Circulation. 2003:108:2154-69.

6. Bhatt DL, Steg PG, Ohman EM, et al. International prevalence, recognition, and treatment of cardiovascular risk factors in outpatients with atherothrombosis. JAMA. 2006:295:180-9.

7. Steg PG, Bhatt DL, Wilson PWF, et al. One-year cardiovascular event rates in outpatients with atherothrombosis. JAMA. 2007:297:1197-206.

8. Ramos LF, Shintani A, Ikizler TA, Himmelfarb J. Oxidative stress and inflammation are associated with adiposity in moderate to severe CKD. J Am Soc Nephrol. 2008;19:593-9.

9. Cottone S, Lorito MC, Riccobene R, Nardi E, Mule G, Buscemi S, Geraci C, Guarneri M, Arena R, Cerasola G. Oxidative stress, inflammation and cardiovascular disease in chronic renal failure. J Nephrol. 2008;21:175-9.

10. Kim JA. Reciprocal relationships between insulin resistance and endothelial dysfunction: molecular and pathophysiological mechanisms. Circulation. 2006;113(15):1888-904

11. Kobayashi S, Oka M, Maesato K, Ikee R, Mano T, Moriya H, Ohtake T. Coronary artery calcification, ADMA, and insulin resistance in CKD patients. CJASN. 2008;3:1289-95

12. Kenney KR. Rheology: overlooked component of vascular disease. Clin Appl Thromb Hemost. 2003;9:93-9.

13. Kobayashi S, Okamoto K, Maesato K, Moriya H, Ohtake T. Important role of blood rheology in atherosclerosis of patients with hemodialysis. Hemodial Int. 2005:9:268-74.

14. Kobayashi S, Miyamoto M, Kurumatani H, Oka M, Maesato K, Mano T, Ikee R, Moriya $\mathrm{H}$, Ohtake T. Increased leukocyte aggregates are associated with atherosclerosis in patients with hemodialysis. Hemodial Int. 2009;13:286-92.

15. Aulivola B, Hile CN, Hamdan AD. Major lower extremity in patients with end-stage renal disease. Arch Surg. 2004;139:395-9.

16. Howard J, O'Leary DH, Zaccaro D, Haffner S, Rewers M, Hamman R, Selby JV, Saad MF, Savage P, Bergman R. Insulin sensitivity and atherosclerosis. Circulation. 1996;93:1809-17.

17. Moorhead JF, Chan MK, Varghese Z. The role of abnormalities of lipid metabolism in the progression of renal disease. In: Brenner BM, Stein JH, editors. The progressive nature of renal disease. New York: Churchill Livingston; 1986. p. 133-49.

18. Ikeda T, Gomi T, Hirawa N, Sakurai J, Yoshikawa N. Improvement of insulin sensitivity contributes to blood pressure reduction after weight loss in hypertensive subjects with obesity. Hypertension. 1996:27:1180-6.

19. Mak RHK, DeFronzo RA. Glucose and insulin metabolism in uremia. Nephron. 1992;61:377-82.

20. Kobayashi S, Maejima S, Ikeda T, Nagase M. Impact of dialysis therapy on insulin resistance in end-stage renal disease: comparison of hemodialysis and continuous ambulatory peritoneal dialysis. Nephrol Dial Transplant. 2000;15:65-70

21. Shinohara K, Shoji T, Emoto M, Tahara H, Koyama H, Ishimura E, Miki T, Tabata T, Nishizawa Y. Insulin resistance as an independent predictor of cardiovascular mortality in patients with end-stage renal disease. J Am Soc Nephrol. 2002;13(7):1894-900.

22. Bernardo AP, Oliveira JC, Santos O, Carvalho MJ, Cabrita A, Rodrigues A. Insulin resistance in nondiabetic peritoneal dialysis patients: associations with body composition, peritoneal transport, and peritoneal glucose absorption. Clin J Am Soc Nephrol. 2015;10(12):2205-12.

23. Dzurik R, Spustova $V$, Janekova $K$. The prevalence of insulin resistance in kidney disease patients before the development of renal failure. Nephron. 1995;69:281-5.

24. Vareesangthip $\mathrm{K}$, Tong $\mathrm{P}$, Wilkinson $\mathrm{R}$, Thomas $\mathrm{TH}$. Insulin resistance and adult polycystic kidney disease. Kidney Int. 1997;52:503-8.

25. Fliser D, Pacini G, Engelleiter R, Kautzky-Willer A, Prager R, Franek E, Ritz E. Insulin resistance and hyperinsulinemia are already present in patients with incipient renal disease. Kidney Int. 1998;53:1343-7.

26. Chen J, Muntner P, Hamm LL, Fonseca V, Batuman V, Whelton PK, He J. Insulin resistance and risk of chronic kidney disease in nondiabetic US adults. J Am Soc Nephrol. 2003;14:469-77.

27. DeFronzo RA, Andres R, Edgar P, Walker WG. Carbohydrate metabolism in uremia. Medicine. 1973;52:285-98.

28. DeFronzo RA, Alvestrand A, Smith D, Hendlerm R, Hendler E, Wahren J. Insulin resistance in uremia. J Clin Invest. 1981;65:563-8.

29. DeFronzo RA, Tobin JD, Andres R. Glucose clamp technique: a method for quantifying insulin secretion and resistance. Am J Physiol. 1979;237:E214-23.

30. Kobayashi S, Maesato K, Moriya H, Ohtake T, Ikeda T. Insulin resistance in patients with chronic kidney diseases. Am J Kidney Dis. 2005;45:275-80.

31. Sniderman AD, Furberg CD, Keech A, van Lennep JE R, Frohlich J, Jungner I, Walldius G. Apolipoproteins versus lipids as indices of coronary risk and as targets for statin treatment. Lancet. 2003;361:777-80.

32. de Brito-Ashurst I, Varagunam M, Raftery MJ, Yaqoob MM. Bicarbo supplementation slows progression CKD and improves nutrional status. J Am Soc Nephrol. 2009;20:2075-84.

33. Hosoya K, Minakuchi H, Wakino S, Fujimura K, Hasegawa K, Komatsu M, Yoshifuji A, Futatsugi K, Shinozuka K, Washida N, Kanda T, Tokuyama H, Hayashi $\mathrm{K}$, Itoh $\mathrm{H}$. Insulin resistance in chronic kidney disease is ameliorated by spironolactone in rats and humans. Kidney Int. 2015;87(4):749-60.

34. Goodman GW, Goldin J, Kuizon DB, Yoon C, Gales B, Sider D, Wang Y, Chung J, Emerick A, Greaser L, Elashoff RM, Salusky IB. Coronary artery calcification in young adults with end-stage renal disease who are undergoing dialysis. N Engl J Med. 2000;342:1478-83.

35. Raggi P, Boulay A, Chasan-Taber S, Amin N, Dillon M, Burke SK, Chertow GM. Cardiac calcification in adult hemodialysis patients. A link between endstage renal disease and cardiovascular disease? J Am Coll Cardiol. 2002;39: 695-701.

36. Tamashiro M, Iseki $K$, Sunagawa O, Inoue T, Higa S, Afuso H, Fukiyama K Significant association between the progression of coronary artery calcification and dyslipidemia in patients on chronic hemodialysis. Am J Kidney Dis. 2001;38:64-9.

37. Bursztyn M, Motro M, Grossman E, Shemesh J. Accelerated coronary artery calcification in mildly reduced renal function of high-risk hypertensives: a 3-year prospective observation. J Hypertens. 2003;21:1953-9.

38. Russo D, Palmiero G, Blasio APD, Balletta MM, Andreucci VE. Coronary artery calcification in patients with CRF not undergoing dialysis. Am J Kidney Dis. 2004:44:1024-30.

39. Fox CS, Larson MG, Keyes MG, Levy D, Clouse ME, Culleton B, O'Donnell CJ. Kidney function is inversely associated with coronary artery calcification in men and women free of cardiovascular disease: the Framingham study. Kidney Int. 2004;66:2017-21.

40. Mehrotra R, Budoff M, Hokanson JE, Ipp E, Takasu J, Adler S. Progression of coronary artery calcification in diabetics with and without chronic kidney disease. Kidney Int. 2005;68:1258-66.

41. Arad $Y$, Newtein D, Cadet F, Roth M, Guerci AD. Association of multiple risk factors and insulin resistance with increased prevalence of asymptomatic coronary artery disease by an electron-beam computed tomographic study. Arterioscler Thromb Vasc Biol. 2001:21:2051-8.

42. Stuhlinger MC, Abbasi MC, Chu JW, Lamendola C, McLaughlin TL, Cooke JP, Reaven GM, Tsao PS. Relationship between insulin resistance and an endogenous nitric oxide synthase inhibitor. JAMA. 2002;287: 1420-6.

43. Boger RH, Bode-Borger SM, Szuba A, Philip ST, Chan JR, Oranee T, Terrence FB, Cooke JP. Asymmetric dimethylarginine: a novel risk factor for endothelial dysfunction. Its role in hypercholesterolemia. Circulation. 1998;98:1842-7. 
44. Ito A, Tsao PS, Adimoolam S, Kimoto M, Ogawa T, Cooke JP. Novel mechanism for endothelial dysfunction: dysregulation of dimethylarginine dimethyl aminohydrolase. Circulation. 1999;99:3092-5.

45. Cooke JP. Does ADMA cause endothelial dysfunction? Arterioscler Thromb Vasc Biol. 2000;20:2032-7.

46. Kleinstein JT, Boger RH, Bode-Boger SM, Schaffer J, Barbey M, Koch KM, Frolich JC. Asymmetric dimethylarginine plasma concentrations differ in patients with end-stage renal disease: relationship to treatment method and atherosclerotic disease. J Am Soc Nephrol. 1999;10:594-600.

47. Meinitzer A, Seelhorst U, Wellnitz B, Halwachs-Baumann G, Boehm BO, Winkelmann BR, Matz W. Asymmetrical dimethylarginine independently predicts total and cardiovascular mortality in individuals with angiographic coronary artery disease (the Ludwigshafen risk and cardiovascular health study). Clin Chem. 2007;53:273-83.

48. Valkonen VP, Palva H, Salonen JT, Lakka TA, Lehtimaki T, Laakso J, Laaksonen R. Risk of acute coronary events and serum concentration of asymmetrical dimethylarginine. Lancet. 2001;358:2127-8.

49. Blaha MJ1, DeFilippis AP, Rivera JJ, Budoff MJ, Blankstein R, Agatston A, Szklo M, Lakoski SG, Bertoni AG, Kronmal RA, Blumenthal RS, Nasir K. The relationship between insulin resistance and incidence and progression of coronary artery calcification: the multi-ethnic study of atherosclerosis (MESA). Diabetes Care. 2011;34(3):749-51.

50. Verma S, Buchanan MR, Anderson TJ. Endothelial function testing as a biomarker of vascular disease. Circulation. 2003;108:2054-9.

51. Gawaz MP, Mujais SK, Schmidt B, et al. Platelet-leukocyte aggregates during hemodialysis: effect of membrane type. Artif Organs. 1999;23:29-36.

52. Sarma J, Laan CA, Alam S, Jha A, Fox KA, Dransfield I. Increased platelet binding to circulating monocytes in acute coronary syndromes. Circulation. 2002;105(18):2166-71.

53. Jaar BG, Astor BC, Berns JS, Powe NR. Predictors of amputation and survival following lower extremity revascularization in hemodialysis patients. Kidney Int. 2004:65:613-20.

54. Sumner R. Noninvasive assessment of peripheral arterial occlusive disease. In: Rutherford RB, editor. Vascular disease. 3rd ed. Philadelphia: WB Saunders; 1989. p. 61-111.

55. Prineas RJ, Harland WR, Janzon L, Kannel W. Recommendations for use of non-invasive methods to detect atherosclerotic peripheral arterial disease in population studies. American Heart Association Council on Epidemiology. Circulation. 1982;65:1561A-6.

56. Carter SA. Role of pressure measurements in vascular disease. In: Berstein EF, editor. Vascular diagnosis. 4th ed. St Louis: CV Mosby; 1993. p. 486-512.

57. Yao ST, Hobbs JT, Irvine WT. Ankle systolic pressure measurements in arterial disease affecting the lower extremities. Br J Surg. 1969:56:676-9.

58. Carter SA, Lezack JD. Digital systolic pressures in the lower limb in arterial disease. Circulation. 1971;43:905-14

59. Carter SA. Clinical measurement of systolic pressures in limbs with arterial occlusive disease. JAMA. 1969;207:1869-74.

60. Rutherford RB, Baker JD, Ernst C, Johnston KW, Porter JM, Ahn S, Jones DN. Recommended standards for reports dealing with lower extremity ischemia: revised version. J Vasc Surg. 1997;26:517-38.

61. European Working Group on Chronic Critical Leg Ischemia. Second European consensus document on chronic critical leg ischemia. Circulation. 1991;84:IV1-26.

62. Larsson JAJ, Castenfors J, Agardh CD, Stenstrom A. Distal blood pressure as a predictor for the level of amputation in diabetic patients with foot ulcer. Foot Ankle. 1993;14(5):247-53. 14:247-253.

63. Carter SA. Ankle and toe systolic pressures comparison of value and limitations in arterial occlusive disease. Int Angiol. 1992;11:289-97.

64. Holstein P. Ischaemic wound complications in above-knee amputations in relation to the skin perfusion pressure. Prosthet Orthot Int. 1980;4:81-6.

65. Castronuovo Jr JJ, Adera HM, Smiell JM, Price RM. Skin perfusion pressure measurement is valuable in the diagnosis of critical limb ischemia. J Vasc Surg. 1997:26:629-37.

66. Tsai FW, Tulsyan N, Jones DN, Abdel-Al N, Castronuovo Jr JJ, Carter SA. Skin perfusion pressure of the foot is a good substitute for toe pressure in the assessment of limb ischemia. J Vasc Surg. 2000;32:32-6

67. Okamoto T, Oka M, Maesato $K$, et al. Peripheral arterial occlusive disease is more prevalent in patients with hemodialysis: comparison with the findings of multidetector-row computed tomography. Am J Kid Dis. 2006;48:269-76.

68. O'Hare A. Lower-extremity peripheral arterial disease among patients with end-stage renal disease. J Am Soc Nephrol. 2001;12:2838-47.
69. Leskinen $Y$, Salenius JP, Lehtimaki T, Huhtala $H$, Saha $H$. The prevalence of peripheral arterial disease and medial arterial calcification in patients with chronic renal failure: requirements for diagnostics. Am J Kidney Dis. 2002:40:472-9.

70. De Vinuesa SG, Ortega M, Martinez P, Golcoechea M, Campdera FG, Luno J. Subclinical peripheral arterial disease in patients with chronic kidney disease: prevalence and related risk factors. Kidney Int Suppl. 2005;67:S44-7.

71. Han KH, O'Neill WC. Increased peripheral arterial calcification in patients receiving Warfarin. J Am Heart Assoc. 2016;5:1.

72. Kestenbaum B1, Sampson JN, Rudser KD, Patterson DJ, Seliger SL, Young B, Sherrard DJ, Andress DL. Serum phosphate levels and mortality risk among people with chronic kidney disease. J Am Soc Nephrol. 2005;16:520-8.

73. Isakova T, Ix JH, Sprague SM, Raphael KL, Fried L, Gassman JJ, Raj D, Cheung AK, Kusek JW, Flessner MF, Wolf M, Block GAJ. Rationale and approaches to phosphate and fibroblast growth factor 23 reduction in CKD. J Am Soc Nephrol. 2015;26:2328-39.

74. Kuro-o M. Klotho in chronic kidney disease-what's new? Nephrol Dial Trans. 2009;24:1705-8.

75. de Boer $\mathbb{H}$, Kestenbaum B, Shoben AB, Michos ED, Sarnak MJ, Siscovick DS. 25-Hydroxyvitamin $D$ levels inversely associate with risk for developing coronary artery calcification. J Am Soc Nephrol. 2009;20:1805-12.

76. Seiler S, Rogacev KS, Roth HJ, Shafein P, Emrich I, Neuhaus S, Floege J, Fliser D, Heine GH. Associations of FGF-23 and sKlotho with cardiovascular outcomes among patients with CKD stages 2-4. Clin J Am Soc Nephrol. 2014;9:1049-58.

77. Scialla JJ, Xie H, Rahman M, Anderson AH, Isakova T, Ojo A, Zhang X, Nessel L, Hamano T, Grunwald JE, Raj DS, Yang W, He J, Lash JP, Go AS, Kusek JW, Feldman $\mathrm{H}$, Wolf M. Chronic renal insufficiency cohort (CRIC) study investigators. Fibroblast growth factor-23 and cardiovascular events in CKD. J Am Soc Nephrol. 2014;25:349-60.

78. Zoccali C, Maio R, Mallamaci F, Sesti G, Perticone F. Uric acid and endothelial dysfunction in essential hypertension. J Am Soc Nephrol. 2006; 17(5):1466-71.

79. Weiner DE, Tighiouart H, Elsayed EF, Griffith JL, Salem DN, Levey AS. Uric acid and incident kidney disease in the community. J Am Soc Nephron. 2008;19(6):1204-11.

80. Sircar D, Chatterjee S, Waikhom R, Golay V, Raychaudhury A, Chatterjee S, Pandey R. Efficacy of febuxostat for slowing the GFR decline in patients with CKD and asymptomatic hyperuricemia: a 6-month, double-blind, randomized, placebo-controlled trial. Am J Kidney Dis. 2015;66(6):945-50.

81. Zang W, Iso H, Murakami Y, Miura K, Nagai M, Sugiyama D, Ueshima H, Okamura T, EPOCH-JAPAN Group. Serum uric acid and mortality from cardiovascular disease: EPOCH-JAPAN study. J Atheroscler Thromb. 2016;23: 692-703.

82. Ross R, Glomset JA. The pathogenesis of atherosclerosis. N Engl J Med. 1976;295:369-77.

83. Ross R. The pathogenesis of atherosclerosis — an update. N Engl J Med. 1986:314:488-500

84. Drüeke TB. Arterial intima and media calcification: distinct entities with different pathogenesis or all the same? Clin J Am Soc Nehrol. 2008:3:1583-4.

85. Shuto E, Taketani Y, Tanaka R, Harada N, Issiki M, Sato M, Nashiki K, Amo K, Yamamoto H, Nakaya Y, Takeda E. Dietary phosphorus acutely impairs endothelial function. JASN. 2009;20:1504-12.

86. Wolf M. Forging forward with 10 burning questions on FGF23 in kidney disease. J Am Soc Nephrol. 2010:21:1427-35. 